\title{
Research on the Construction of Professional Manager in State-Owned Enterprises
}

\author{
Xingyuan Huang \\ Dalian Polytechnic University \\ School of Management \\ Dalian, Liaoning Province, China
}

\author{
Yangyang $\mathrm{Si} *$ \\ Dalian Polytechnic University \\ School of Management \\ Dalian, Liaoning Province, China
}

\begin{abstract}
Actively promoting the professional manager system is an important driving force for the reform and development of state-owned enterprises. However, the status quo of professional managers in China is not optimistic. The purpose of this paper is to analyze the problems existing in the current construction of professional managers in state-owned enterprises, and to propose practical and feasible measures. This paper uses a combination of qualitative and quantitative research methods. At the end of the paper, four specific measures are proposed. The first is to improve the human resources management system of professional managers of state-owned enterprises. The second is to build a scientific and reasonable performance evaluation system. The third is to improve the incentive mechanism for professional managers of state-owned enterprises. The fourth is the exit mechanism of the professional managers of the national enterprises.
\end{abstract}

Keywords-professional manager; state-owned enterprises; team building

\section{INTRODUCTION}

The Third Plenary Session of the 18th CPC Central Committee clearly stated: To establish a professional manager system and better play the role of entrepreneurs, state-owned enterprises should reasonably increase the proportion of market-based selection and employment. The reform of state-owned enterprise cadre system and the establishment of a professional manager system will become the top priority of the next state-owned enterprise reform.

However, many problems have been encountered in the process of state-owned enterprise reform. Among them, the lack of professional manager, the shortage of professional manager of state-owned enterprises, the imperfect market construction of professional manager of state-owned enterprises, and the dislocation of professional manager of state-owned enterprises Problems such as the phenomenon of defeating morality have seriously restricted the construction of professional manager of state-owned enterprises.[1]

\section{RESEARCH IDEAS AND METHODS}

The research ideas and methods of this paper are as follows:

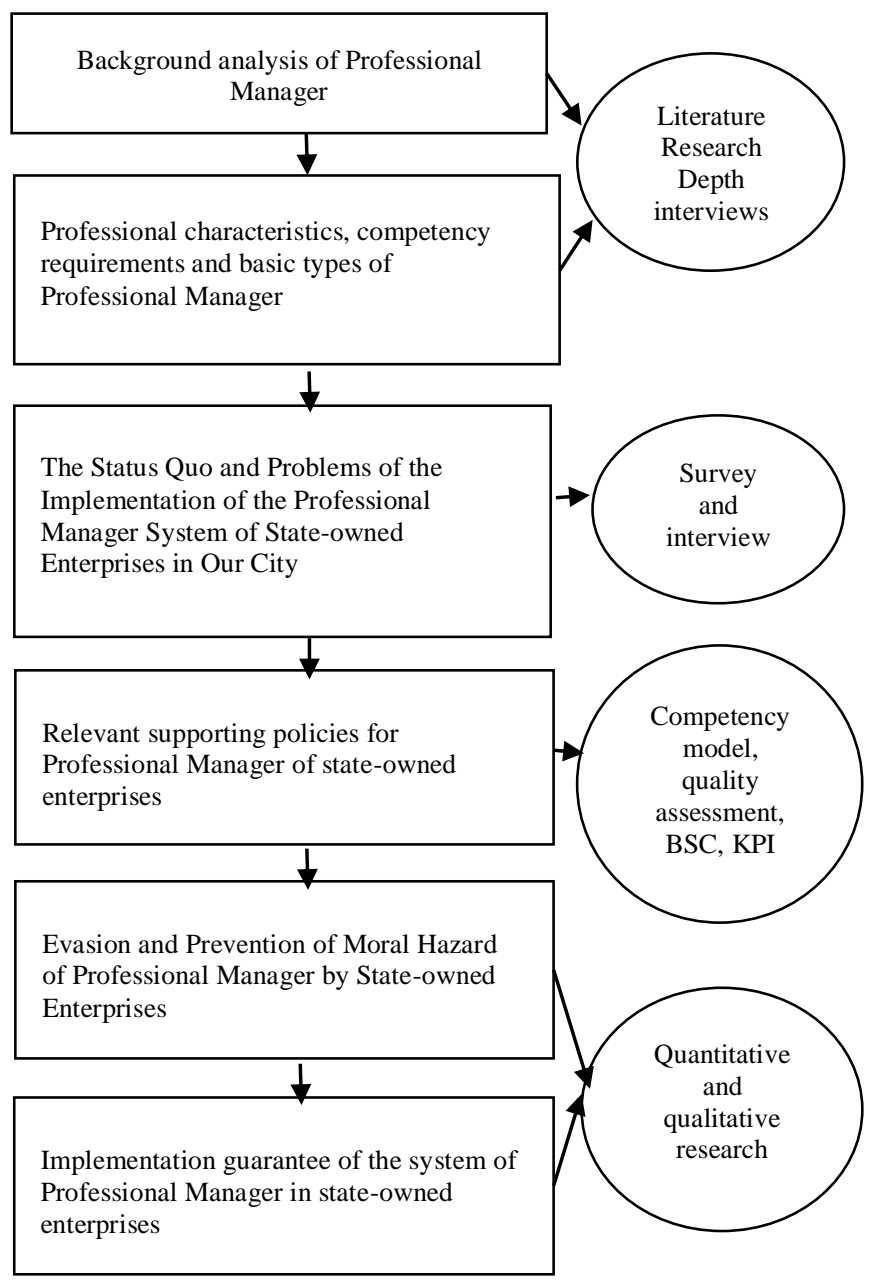

Fig.1. Logical structure diagram

This article will firstly analyze the background, professional characteristics, ability requirements and basic types of professional managers. Following this, this paper will discuss the status quo and problems of the implementation of the professional manager system of state-owned enterprises in our city. Finally, it will put forward reasonable suggestions for the professional manager system of state-owned enterprises. 


\section{The Problems In the Process of Building A Professional Manager TeAm of STATE-OWNED ENTERPRISES}

\section{A. The number of Professional Manager in state-owned enterprises is scarce}

As early as 2002, China issued a document proposing "building a professional manager team". However, the Third Plenary Session of the 18th CPC Central Committee first proposed that state-owned enterprises should "establish a professional manager system and better play the role of entrepreneurs". Compared with the developed capitalist countries in Europe and America, China realizes that the team of professional manager with clear division of labor is late. And state-owned enterprises have realized the importance of the construction of professional manager in recent years.[2] In addition, the nature of state-owned enterprises has increased the scarcity of professional manager. Compared with private enterprises, state-owned enterprises have stricter qualification standards for professional manager.

The late construction of professional manager and the high standards of qualifications have resulted in the current shortage of market supply for professional manager of state-owned enterprises in China. The supply and demand are seriously unbalanced, unable to meet the needs of deepening the reform of state-owned enterprises and cannot provide innovative and sustainable development for state-owned enterprises.[3]

\section{B. State-owned enterprise Professional Manager Recruitment market is not perfect}

Generally speaking, the source of professional manager has two aspects. One is internal recruitment, and the other is external competition. At present, most of the professional managers of state-owned enterprises in China are transformed from internal personnel of state-owned enterprises. This relatively single selection method leads to many problems. First, the age structure tends to age. The majority of state-owned enterprise executives are over 45 years old. This age structure will limit the company's innovation and development to a certain extent. Second, the knowledge structure may lag behind the development of the times. In the past decade or so, the rapid development of Internet and AI intelligence has accelerated the updating of knowledge information.[4] Different age groups not only indicate that the starting point for receiving education is different. And their acceptance and mastery of new knowledge is different. Therefore, this imperfect recruitment method affects the selection of talent quality.[5]

\section{The performance evaluation mechanism of state-owned enterprises to professional manager needs to be improved}

According to the questionnaire survey, only $38.1 \%$ of the respondents believe that the evaluation results of state-owned enterprise leaders are "close" to personal compensation. $55.55 \%$ of the respondents considered "general" . From the survey data and interviews, it is understood that state-owned enterprises have much room for improvement in the performance evaluation mechanism of professional managers. The assessment indicators are not clear, the assessment results lack feedback, and mixed with a strong political color, the performance evaluation mechanism has not yet formed a complete mechanism.[7] Undoubtedly, this vague performance appraisal mechanism of state-owned enterprises is not effective in attracting, retaining and motivating professional managers.

\section{Business management has a role of dislocation}

Since most of the professional managers of state-owned enterprises are internally transformed, they are appointed by the administrative department and rarely openly recruited for employment. Therefore, it is difficult to truly achieve separation of government and enterprise. This has led to the unclear positioning of professional managers.[8] They still uphold the characteristics of their work in the original post the conservative mentality of "not seeking merit, but seeking nothing". And they have a strong political color when making business decisions, rather than pursuing profits as their business objectives.

\section{Suggestions AND IMPROVEMENT MEASURES}

\section{A. Improving the human resource management system of Professional Manager of state-owned enterprises}

\section{1) Improving the selection mechanism}

State-owned enterprises should enrich the channels for selecting and hiring professional managers, reduce the proportion of internally selected talents, and appropriately increase the market-based selection methods. When state-owned enterprises use internal selection methods for selection, they should minimize excessive subjective judgments. They should consider a variety of factors to select and minimize the interference of political factors.

When adopting a market-based selection method, enterprises must conduct demand analysis according to their business strategies. Enterprises should develop a standardized recruitment process, clear and rigorous recruitment standards, and uphold the principles of fairness, openness. State-owned enterprises should build a competency model for state-owned enterprise managers as a basis for recruitment.

\section{2) Establishing a training mechanism}

Whether it is internal selection or market recruitment, establishing a training mechanism is an urgent task for state-owned enterprises to build a professional manager team of state-owned enterprises.

The internally selected talents are very familiar with the company and can work quickly. But their identity changes, and their work content and responsibilities change. And the above mentioned internal selection of talent may be older. Therefore, it is necessary to train them. Training should take into account the learning of market-oriented knowledge and the renewal of new knowledge. Therefore, a continuous learning and training mechanism can be established to conduct qualification training to obtain qualification certification. State-owned enterprises can even cooperate with private enterprises. Let it learn communication with professional managers of private enterprises. So that the professional managers of state-owned enterprises have a clearer positioning.

The adoption of market-based selection means that companies choose to have more anti-counterfeiting and can inject new vitality into the enterprise. However, this is likely to 
result in "consistency" and conflicting values. Therefore, it is necessary to design the content of the training according to the characteristics of the company. Let it integrate into the company as soon as possible, understand and accept the corporate culture.

\section{B. Building a scientific and reasonable performance evaluation system}

State-owned enterprises can flexibly use balanced scorecards for performance appraisal. When designing the performance indicators of professional manager in state-owned enterprises, they must be decomposed to the extent that they cannot be subdivided. Each performance indicator should have clear evaluation indicators and should be more quantitative indicators to reduce qualitative indicators. Enterprises can appropriately reduce basic salary according to the situation, increase the performance compensation of professional manager, and minimize internal unfairness.

\section{Improving the incentive mechanism for Professional Manager of state-owned enterprises}

\section{1) Material incentives}

For state-owned enterprises that have passed the high-speed development period, setting incentives for professional manager may increase their motivation. For state-owned enterprises that are in the growth stage, medium and long-term equity incentives are more effective. Therefore, it is necessary to conduct research in different stages of industry, sub-industry, and sub-enterprise, and formulate corresponding incentive plans according to the characteristics of different state-owned enterprises.

\section{2) Spiritual motivation}

According to Maslow's hierarchy of needs, for professional manager of state-owned enterprises, they want to get the attention of the organization, take up challenging work, and realize their own value. Therefore, enterprises can hold "excellent state-owned enterprise professional manager selection", "honorary title" and other activities. According to the results of its performance appraisal and the needs of professional manager, education and training will not only improve their management ability, but also enable them to feel their own training and work harder.

\section{The exit mechanism of the Professional Manager of the national enterprises}

State-owned enterprises should establish an exit mechanism based on performance appraisal data, and clarify the exit criteria and conditions of professional manager. If the professional manager is transferred for the same reason, I must re-competition for the post I am taking up. Dismissed in accordance with the group's corresponding dismissal procedures for resignation matters.

\section{SUMMARY}

This paper conducts an in-depth investigation and research on the construction of professional managers in state-owned enterprises, and finds out the problems existing in the process of building professional managers in state-owned enterprises. According to the construction of the competency model, the article proposes the standards for the recruitment and selection of professional managers of state-owned enterprises, the salary management system suitable for professional managers, and the series of training and career management to promote the development of professional managers. Based on the goal of state-owned enterprise reform and the implementation of modern enterprise system, this paper establishes a performance appraisal and comprehensive evaluation system for professional managers of state-owned enterprises. And it elaborates on important issues such as further improving the constraint mechanism.

\section{REFERENCES}

[1] Jia Hongna. Research on the main influencing factors of the professionalization of managers of state-owned enterprises [D]. Anhui University, 2018. (In Chinese)

[2] Yang Yansong. Research on the Construction and Management of Professional Manager in State-owned Enterprises[J].Human Resources Management.2017(02) (In Chinese)

[3] Lu Wei. Selection and Management of Professional Manager in State-Owned Enterprises Based on Talent Inventory-Taking Y Group as an Example[J]. China Human Resources Development, 2016(14): 36-43. (In Chinese)

[4] Zhong Ming. Vigorously promote the construction of Professional Manager system [J]. Enterprise Management, 2015 (02): 1. (In Chinese)

[5] Li Jingjing. Research on the Reform of Professional Manager System from the Perspective of State-owned Assets Management[J]. Building Materials and Decoration, 2017(37): 163-164. (In Chinese)

[6] Chen Jing. Thoughts on the Construction of Professional Manager System in State-owned Enterprises[J]. Integrated Circuits Applications, 2017, 34(04): 86-89. (In Chinese)

[7] Yang Yueping. Exploratory Research on the Implementation of Professional Manager System in Xiangdian Group[J].Research on Modern State-Owned Enterprises,2016(16):209-210. (In Chinese)

[8] Yu Jigang. On the Professional Manager System and the Reform of State-owned Enterprises[J]. Modern Economic Information, 2015(02): 101. (In Chinese). 